\title{
How Physicochemical Parameters of WATER CHANGE WITH DistanCE IN A LAKE: CASE STUdY LAKE BUNYONYIINKIGEZI
}

\author{
Mukasa-Tebandeke I.Z ${ }^{1}$, Karume I. $^{2}$, Ssebuwufu J. ${ }^{3}$, \\ Wasajja H.Z ${ }^{4}$, Nankinga, ${ }^{4}$, Kansiime $Z^{1}$ \\ ${ }^{1}$ Department of Chemistry, Faculty of Science, Kabale University, Uganda \\ ${ }^{2}$ Chemistry Department, School of Physical Sciences, \\ College of Natural Sciences, Makerere University, Uganda \\ ${ }^{3}$ University of Kisubi, Uganda \\ ${ }^{4}$ Departments of Earth Sciences, Wesleyan University, Connecticut USA
}

\begin{abstract}
Pollution resulting from unsustainable agricultural and urbanization activities in the Ruhezamyenda and Bunyonyi catchments are threatening lake Bunyonyi. These have led to high chemical oxygen demand (COD), electrical conductivity, turbidity, $\mathrm{pH}$, iron (II) concentration and low dissolved oxygen (DO $\mathrm{O}_{5}$ ). In this study we have investigated the how COD, turbidity, $p H$, concentration of iron, total suspended solids, total nutrients and $\mathrm{DO}_{5}$ of water changed with distance in lake. Water sampled from different distances in the lake filtered using Whatman paper at ambient temperatures was tested for COD, electrical conductivity, turbidity, total nutrients, iron, hardness and $\mathrm{DO}_{5}$. COD was $20.8 \pm 0.03 \mathrm{mg} / \mathrm{L}$ to $16 \pm$ $0.03 \mathrm{mg} / \mathrm{L}$; total hardness was $16.5 \pm 0.2 \mathrm{mg} / \mathrm{L}$ to $18.6 \pm 0.3 \mathrm{mg} / \mathrm{L}$ total nitrate was $103.5 \pm 2 \mathrm{mg} / \mathrm{L}$ to $88 \pm 3$ $\mathrm{mg} / \mathrm{L}$; total phosphate was $100.8 \pm 2.5$ to $87 \pm 3 \mathrm{mg} / \mathrm{L}$; high TSS values from $3.4 \pm 0.1 \mathrm{mg} / \mathrm{L}$ to $2.5 \pm 0.1$ $\mathrm{mg} / \mathrm{L}$ showed contamination of water. As $\mathrm{pH}$ decreased from $8.3 \pm 0.03$ to $7.6 \pm 0.04$ revealed that bases were getting removed. The turbidity dropped from $25.7 \pm 0.3 \mathrm{NTU}$ to $20 \pm 2 \mathrm{NTU}$ due settling down of sediments. Iron (II) concentration ranging from $1.1 \pm 0.1$ to $0.8 \pm 0.1 \mathrm{mgL}^{-1}$. Dissolved oxygen decreased from $7.9 \pm 0.3 \mathrm{mg} / \mathrm{L}$ to $4.8 \pm 0.2 \mathrm{mg} / \mathrm{L}$ indicating surface water can uphold life of aquatic organisms. Total hardness ranged from $0.22 \pm 0.05$ to $0.19 \pm 0.05 \mathrm{mg} / \mathrm{L}$ Electrical conductivity was high and ranged from $130 \pm 5$ to $150 \pm 5 \mu \mathrm{S} / \mathrm{cm}$ indicating presence of electrolytes. Lake Bunyonyi water is not greatly polluted, but requires to be safe guarded against poor unsustainable agricultural practices, sewage draining from towns, schools and hotels in nearby settlements.
\end{abstract}

\section{KEYWORDS}

Chemical oxygen demand (COD), Turbidity, Nutrient concentration, Concentration of iron, Electrical conductivity, Total hardness, Pollution, Bunyonyi catchment, $\mathrm{pH}$.

\section{INTRODUCTION}

Bunyonyi is the largest of lake in the Kigezi region, lying at 1,973 meters above sea level (Beadle, 1966; Green, 2009) and it receives water from Rwanda through river Kabrita but also has an outlet to lake Mutanda through river Ruhwezamyenda. Lake Bunyonyi, the place of many little birds, is located in south western Uganda within Kabale, Rubanda and Kisoro districts, close to the border of Rwanda and Uganda with a width of $7 \mathrm{~km}$ and length of $25 \mathrm{~km}$.. This calm lake attracts migratory birds during winter, making it an ideal destination for Uganda birding safaris. It is known for water sports and is a remarkable destination for both foreign and domestic 
travelers. Lake Bunyonyi lies in the Ruhezamyenda catchment an area with two rain seasons in March to May and September to November, discharges to river Ruhezamyenda in the Albert Nile basin. The geology of Ruhezamyenda catchment is characterized by volcanic rock, and the soils are mainly ferralitic/ferralsols (Osiru, 2006) with peat soils in the swampy areas (Rukundo, 2015).The valleys are used for growing potatoes, maize, beans, peas , sorghum, millet (Crerar\&Akurut, 2017; Osiru, 2006) This creates fast lanes for runoff waters from the steep slopes to the lake. Despite the steep slopes there is very little evidence of terracing throughout the catchment. As a result, there are high levels of erosion, especially during intense rainfall events. This results in soil being washed from the upper slopes to the lower slopes and valley bottoms thus leading to pollution.

The hills enclosing the lake used to be terraced to reduce soil erosion to this fresh water resource in Kigezi region. Although lake Bunyonyi is threatened by pollution, it remains the main fresh water resource in the Kigezi as it is the largest lake in the area. Hotels and schools have been accused of draining sewerage to the lake. Unsustainable methods of agriculture, coupled to draining of channels for agricultural and human settlement purposes have led to silting and eutrophication of catchment areas to the lake as the peasants do not adhere to the environmental guidelines to leave 100 meters between the Lake and their gardens. This greatly affects the beauty of this tourist site. Although the importance of wetlands in sustaining rural livelihoods is well known in Uganda, widespread drainage and habitat degradation occurs because of urbanization and high population densities; the resulting land pressure has led to considerable translocation of rural householders, which contribute to breakdown of collaborative management of the wetlands. Towns on shores of lake Bunyonyi include Kyevu and Muko. Although wetlands provide food, timber for construction and cooking as well as leisure and transport, thereby ensuring hospitality, in Uganda they are under increasing exploitation is leading to depletion without adequate conservation measures. The means utilized to raise economic gains from wetlands by the rural poor result in escalated levels of soil erosion which leads to deterioration of nearby water resources.

Studies aimed at finding out whether the conditions in lakes of Kabale, Kisoro and Rukungiri would enable growth of fishing industry on them have been documented with results revealing that all lakes had high fish production potential but the variation in water quality, resulting from human activities may impart negatively on fish productivity if not remedied. (Tibihika et al 2016). Anthropogenic activities in the lakes of Africa have caused mass extinction of aquatic fauna caused by environmental changes (Hecky, 1993) Most research studies in Uganda focus lakes Victoria, Albert, Kyoga, Edward and George (Akrut, et al , 2016; Mukasa-Tebandeke et al, 2020; Ayieko et al., 2010; Hecky et al., 2010), less attention is put on the numerous minor, satellite lakes in the south (Kizito et al., 1993) yet anthropogenic activities threaten aquatic fauna and flora in them.

Many studies on L. Bunyonyi focused on limnology. Research results have revealed lakes in Kigezi to be pooratfish productivity (Worthington, 1932; Worthington and Ricardo, 1936; Kizito et al, 1993; Tibihika et al, 2016) because they revealed diminishing phytoplankton populations resulting from increased anthropogenic activities in the catchment areas to the lakes resulting from population growth in the urban areas on the slopes surrounding the lake basins. Fish productivity is directly related to the physicochemical and biochemical properties of water bodies and knowledge of how these properties vary would go a long way in facilitating means of increasing fish productivity. So positive interventions like restocking to improve fish productivity, both the limnological and physicochemical aspects of the water bodies should be well documented. 
Limnological studies on lake Bunyonyi and other lakes in the Kigezi region revealed the complete absence of macro invertebrate species/orders from some lakes and this was related to variations in water quality (Green 1976). The variations in quality of water were attributed to the differences in-stream and catchment degradation along the lake shores resulting from urbanization, unsustainable agricultural practices and industrialization (Elias et al, 2014)and this led to complete absence or/and emergence of new macro vertebrate taxa that can withstand environmental changes of the time (Elias et al., 2014, Likens, 2010).

Electrical conductivity expresses the ability of water to conduct electric current. It is useful for estimating the concentration of the total dissolved electrolytes in an aquatic environment (IEPA, 1998). Lakes containing water with high $\mathrm{pH}$ have high conductivity values (Beadle, 1966; Kizito et al., 1993; IEPA, 1998). The conductivity of water from lakes like Nakasanda, Kayumbu was attributed to low concentrations of calcium, magnesium, potassium and sodium ions (Tibihika et al 2016). However, presence of carbonates and hydrogen carbonates in presence of calcium, and magnesium ions in the same water resource will impart high $\mathrm{pH}$ and hardness to the water in addition to high conductivity. Alkalinity of a water mass depends on the formation and nature of soils surrounding the water body or bedrock (Linntech, 2013). Highly alkaline water resources lie in areas containing limestone because the water dissolves calcium carbonate and the carbon dioxide dissolved in water transforms it to the hydrogen carbonate (Matagi, 2004 and Grant, 2006). High $\mathrm{pH}$ ranging from 6.5 to 9.0 was reported to be conducive for fish growth and productivity (Magumba 2000; Heydarnejad, 2012). Consequently, hardness, high pH and conductivity of water samples depend on concentrations of metal salts. Availability of metallic and nonmetallic ions in lake waters increases conductivity of a water mass and this influences distribution and types of aquatic organisms that survive in that water ecosystem (Gupta and Mrinal, 2013)

Ruhezamyenda catchment is the watershed across which all water that reaches lake Bunyonyi flows. Anthropogenic activities in watersheds affect the quality of surface, drinking and recreation water. Proliferation of algae in water masses resulting from fertilizers in runoff water from agricultural fields disturbs health of watersheds (Bellir, 2013). Polluted watersheds affect wildlife, is harmful to man, and affects aquatic life, offset changes in the ecosystems (EPA). Introduction of fertilizers in water bodies increase rate of growth of algae and weeds in water (Srinvasan, 2011).

Oxygenation of water masses removes phosphates and nitrates by converting them to solid sediments at floor of lake and this improves quality of the water mass (Kennedy et al. 2018). The anoxic nature of lake Bunyonyi leads to high nutrient concentrations in water sampled from it.

As microorganism proliferate in a water body, toxins like ammonia increase in addition to nitrates and nitrites. Accumulation of nutrients in water bodies result in nutrient pollution which disrupts aquatic life (Jiang et al. 2006). In the Ruhezamyeda catchment agricultural practices are $\mathrm{n}$ the rise coupled to use fertilizers and manure in poorly managed farms; reclamation of marshland and creation of urban centers and school have significantly contributed to increase in nutrient load in the streams that drain to lake Bunyonyi. Increased agricultural practices involving marshland reclamation in the Ruhezamyenda catchment have led to increased sediment and nutrient loading in the lake through non-point source pollution (Machiwa, 2003). Pollutants affecting the quality of water in lake Bunyonyi must largely arise from non-point sources especially after rain because soil erosion coupled to surface runoff from the steep slopes in the Ruhwezamyenda catchment area and intensive agricultural practices must load the lake more prominently in a manner similar to what was reported about Murchison bay of lake Victoria (Banadda et al.2009). The revelation that 55\% of total phosphorous in put in lake Victoria arises from municipal waste and agricultural fields (Tamatamah et al 2005) leaves us guessing about 
how much enters lake Bunyonyi. The extensive growth of algae in the Murchison bay was explained as arising from high loads of nutrients in water mass caused by high levels of pollution (Cozar et al. 2007; Haande et al. 2011) similar effects are expected for lake Bunyonyi waters. The quality of water in the Bunyonyi catchment must be affected by the high population and unsustainable agricultural practices of the populace much the same way as that of the Murchison Bay was shown to be influenced by nutrients loading in runoff from the catchment and urban centers upstream (Cózar et al. 2007; Bracchini et al. 2007). Bunyonyi waters must be eutrophic due to the very high total nitrate content (Tibihika et al. 2016) because nitrogen was reported to bring eutrophication to the Murchison Bay (Haande et al. 2011; Ssebiyonga et al. 2013).

As water runs over and through the Ruhezamyenda catchment, it picks and carries contaminants and soil. If untreated, pollutants wash directly to Bunyonyi catchment. The contaminants may infiltrate the ground water, and concentrate in streams wherefrom they are carried to the lake. Agricultural practices in the hinterland to Bunyonyi catchment greatly affect the purity of water in the lake (Singh et al. 2018). The presence of homes, schools, hotels and large agrictural fields in the Ruhwwezamyenda catchment of lake Bunyonyi increased the speed with which running ater approaches the lake. This implies that the natural cleaning action of swaps is overwhelmed and pollutants access the lake with ease in much the same way as was reported elsewhere (Aliet al. 2014).

Whereas the amount of total suspended solids (TSS) and turbidity affect waterways in the world, TSS was reported as the major pollutant which affects waterways (Rugner, 2013). It can be necessary to predict TSS of a wter mass in quality control (Verma et al, 2013). Suspended solids are cause deterioration of quality of water (Bilotta et al. 2008)

While some zooplanktons may disappear when exposed to pollutants like heavy metals and excess nutrients which lead to eutrophication (Wava and Chande, 2004) others may survive the harsh conditions through adaptation.

Most lakes show a decline in dissolved oxygen (DO) with depth but do not turn anoxic, yet it was reported that Bunyonyi turns anoxic at depth near $15 \mathrm{~m}$ in dry seasons and $39 \mathrm{~m}$ in the rainy seasons indicating there occurs mass death of aquatic organisms that live below $15 \mathrm{~m}$ due to lack of oxygen (Hughes, 1992, Tibihika et al 2016) and as a consequence levels of nutrients rise in the water.

This study aimed at investigating how physicochemical characteristics of water change with distance into the lake.

\section{MAterials ANd Methods}

\section{Study area}

The study was carried out in Lake Bunyonyi basin in Uganda, Figure 1b, located at $1^{\circ} 20^{\prime} 42^{\prime \prime}$ South and $29^{\circ} 51^{\prime} 1$ " East. Ruhwezamyenda catchment has many deep valleys in an area of over $300 \mathrm{~km}^{2}$ lying at nearly $2000 \mathrm{~m}$ above sea level (Kristan et al, 2006) The soils are pf the old precambrian period made of metamorphic granitoids (Chemining wa et al. 2003) and are use in growing beans, maize, potatoes, peas and vegetables (Osiru, 2006). Lake Bunyonyi is surrounded by steep escarpments that allow gentle flow of winds on its surface. As can be observed in Figure 1a, the waters of Bunyonyi are always calm without tides. 
International Journal of Advances in Chemistry (IJAC) Vol. 7, No.1/2/3/4, November 2021

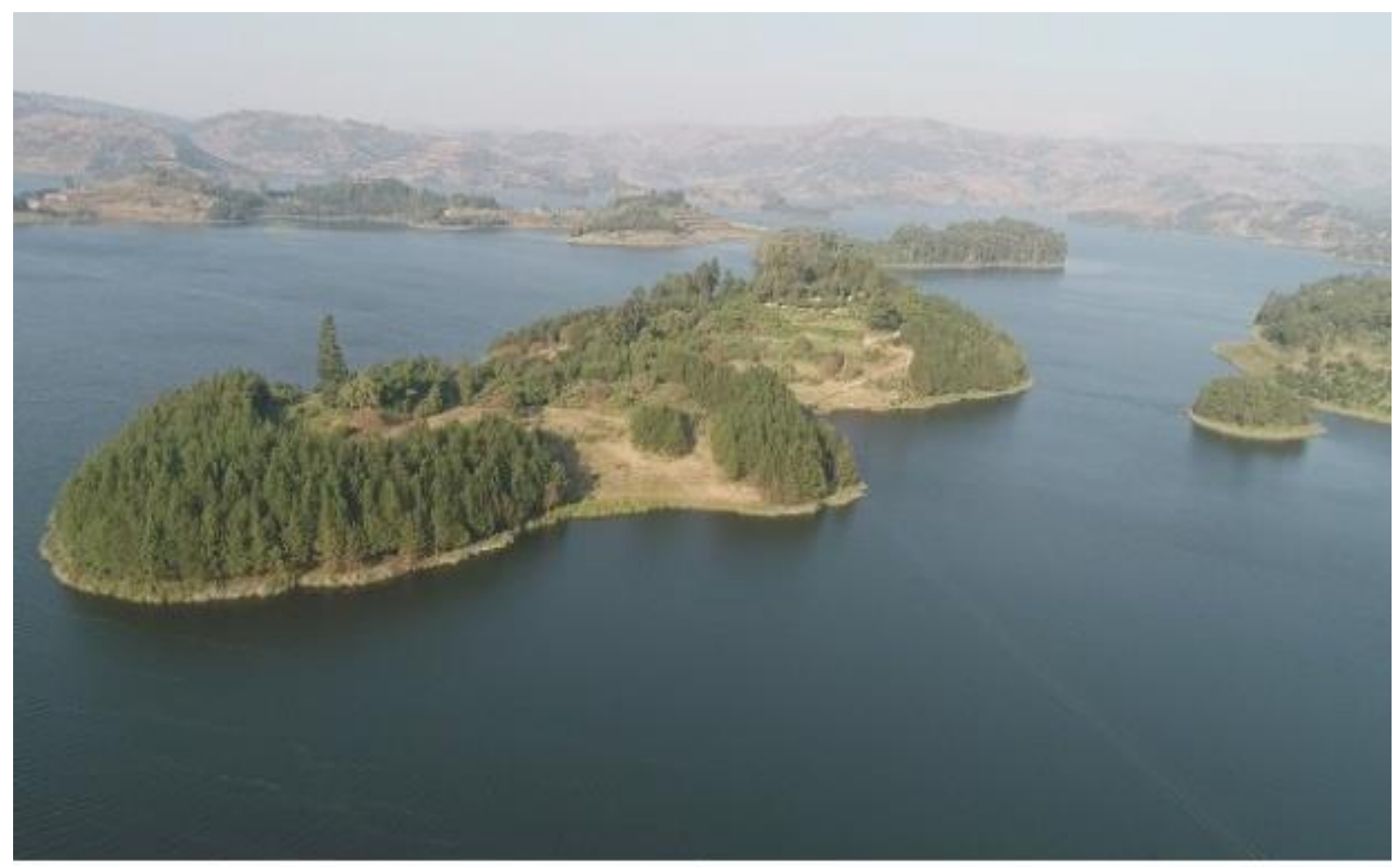

Figure 1a. Appearance of lake Bunyonyi and some islands

The non-turbulent nature of the lake may not easily allow exchange of oxygen with the atmosphere unless it rains. The wind blows very gently and tides are very low. Interface between air and water is restricted mainly to water at the surface of the lake, so aeration is minimized.

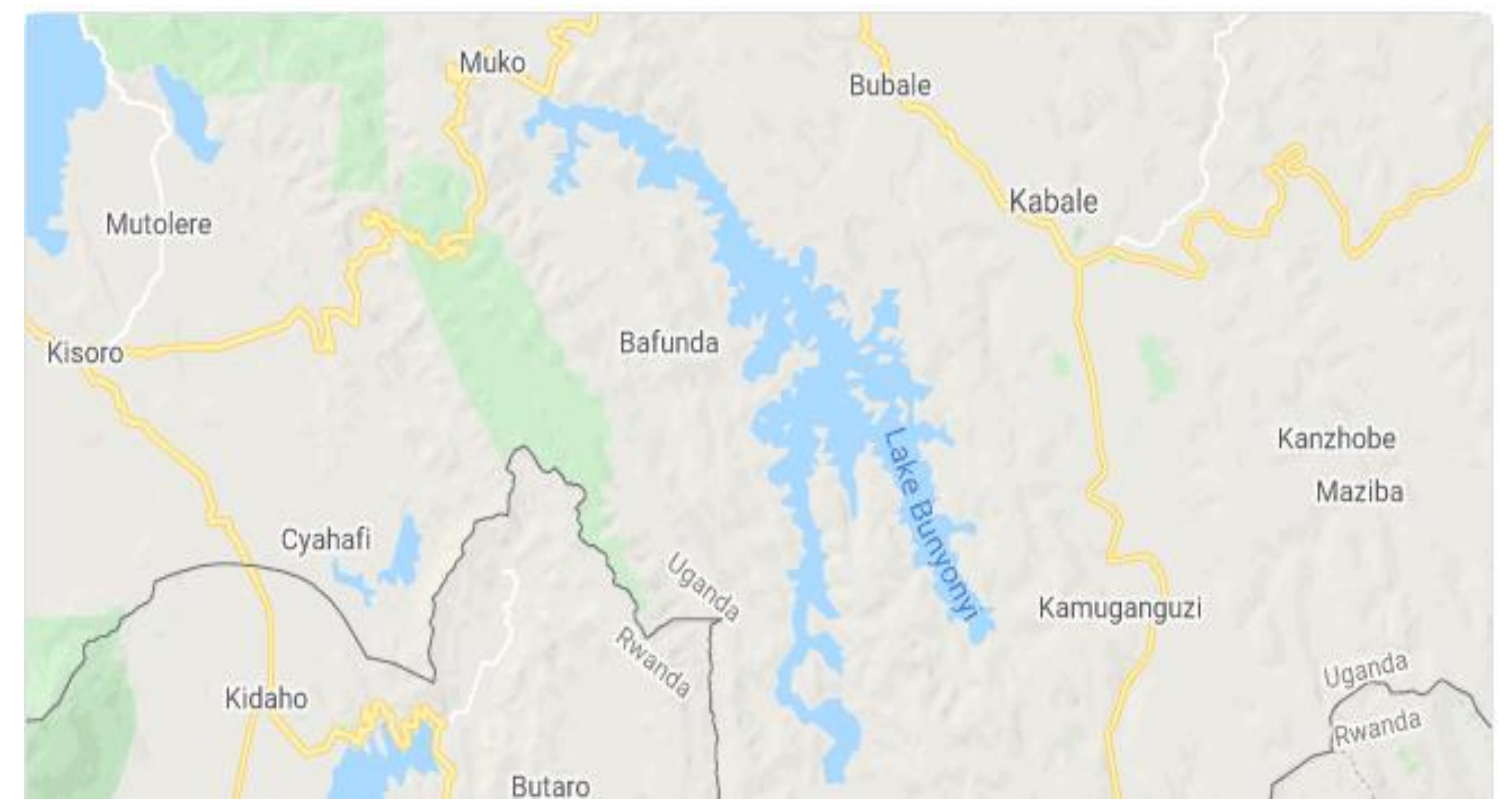

Figure 1b. Lake Bunyonyi and connecting roads 


\section{Sampling}

Water samples (2 L) were drawn at distances of 0,50,100, 150 and 200m in the lake, sealed stored in box before being transported to the laboratory. In the laboratory the water was stored in a freezer at $4{ }^{\circ} \mathrm{C}$ for future use (Abdur, 2013).

\section{Method of determining chemical oxygen demand (COD)}

Potassium dichromate $(6.2 \mathrm{~g})$ was dissolved in distilled water $(1000 \mathrm{~mL})$. The solution was stoppered and stored for future use.

\section{Preparation of silver (I) sulfate-sulfuric acid solution}

Silver (I) sulfate $(10 \mathrm{~g})$ was dissolved in sulfuric acid solution $(500 \mathrm{~mL})$. The mixture was swirled and made up to $1 \mathrm{~L}$ and allowed to stand for 24 hours before being used.

\section{Preparation of mercury (II) sulfate-sulfuric acid solution}

Mercury (II) sulfate $(0.1 \mathrm{~g})$ was dissolved in concentrated sulfuric acid $(5 \mathrm{~mL})$.

\section{Preparation of $0.025 \mathrm{M}$ ammonium iron (II) sulfate solution}

Ammonium iron (II) sulfate $(9.8 \mathrm{~g})$ was dissolved in distilled water $(100 \mathrm{~mL})$ and concentrated sulfuric acid $(20 \mathrm{~mL})$ was added and mixture made up to $1 \mathrm{~L}$ with distilled water.

\section{Ferroin indicator preparation}

Mixture of iron (III) sulfate $(3.5 \mathrm{~g})$ and phenanthroline $(7.3 \mathrm{~g})$ was dissolved in water $(500 \mathrm{~mL})$, and stored for future use.

\section{COD TEST}

Mixture made of sample $(10 \mathrm{~mL})$, glass beads, mercury (II) sulfate $(1 \mathrm{~mL})$ potassium dichromate $(10 \mathrm{~mL})$, silver (I) sulfate $(1 \mathrm{~mL})$ and sulfuric acid $(15 \mathrm{~mL})$ was placed in refluxing apparatus. and heated for two hours, then allowed to cool and transferred to flask. Ferroin indicator (.2 drops) was added and mixture titrated with standard iron (II) sulfate solution to blue end point.

COD was calculated.

\section{Phosphate standard reagent}

Potassium dihydrogen phosphate (1.4 g) was dissolved in distilled water (1 L). (APHA, 1999)

\section{Preparation of Combined Reagent}

$5 \mathrm{~N}$ sulfuric acid was prepared by measuring $98 \%$ concentrated sulfuric acid (14 mL) into a 100 $\mathrm{ml}$ volumetric flask and diluting to the mark with distilled water. Potassium antimonyl tartrate $(0.2742 \mathrm{~g})$ was accurately weighed into a $100 \mathrm{~mL}$ volumetric flask and diluted with distilled water to the mark. Ammonium molybdate (4 g) was mixed with ascorbic acid (1.8 $\mathrm{g})$ and dissolved in distilled water $(100 \mathrm{~mL})$ 
To prepare the combined reagent, $5 \mathrm{~N}$ sulfuric acid $(50 \mathrm{~mL})$, potassium antimonyl tartrate solution $(5 \mathrm{~mL})$, ammonium molybdate solution $(15 \mathrm{~mL})$, and ascorbic acid solution $(30 \mathrm{~mL})$ was measured into a $100 \mathrm{~mL}$ volumetric flask.

\section{Analysis for phosphate ions}

Each of the standards $(10 \mathrm{~mL})$, blank $(10 \mathrm{~mL})$ and samples $(10 \mathrm{~mL})$ were measured into a test tube. combined reagent $(2 \mathrm{~mL})$ was added to the standards, blanks and samples and two drops of phenolphthalein indicator and left to stand for 10 minutes then observed in a UV-visible spectrophotometer.

\section{Determining turbidity}

Distilled water was filtered with whatman filter number 42. Rinse collecting flask at least twice with such filtered water and discard the next $200 \mathrm{~mL}$. The filtered water was used for setting zero of the instrument.

\section{Preparation of Formazine Turbidity Concentrate}

\section{(a) Solution I}

Hydrazine sulphate $\left(\mathrm{NH}_{2}\right)_{2} \mathrm{H}_{2} \mathrm{SO}_{4}(5 \mathrm{~g})$ was weighed to a $500 \mathrm{~mL}$ volumetric flask and distilled water $(500 \mathrm{~mL})$ was added to make up to the mark. The mixture was left to stand for 4 hours.

\section{(b) Solution II}

Hexamethylene tetramine $\left(\mathrm{CH}_{2}\right)_{6} \mathrm{~N}_{4}(50 \mathrm{~g})$ was weighed to a $500 \mathrm{~mL}$ volumetric flask and distilled water $(500 \mathrm{~mL})$ was added to the mark. Equal volumes of solution I and II were mixed to form formazine turbidity concentrate and allowed to stand for 48 hour.

\section{Preparation of Formazine Standard}

Formazine turbidity concentrate $(25 \mathrm{~mL})$ was diluted to 1 liter with turbidity free distilled water to obtain 250 ppm or 100 NTU for setting '100' of the instrument.

\section{Calibrating turbidmeter}

The turbidimeter was switched on. The lid of the sample compartment was opened. A test tube filled with distilled water was inserted in the sample compartment. The lid was closed. The instrument was adjusted to get ' 0 ' displayed on the read out. The lid was opened again. The test tube full of distilled water was replaced with another tube full of formazine standard. The lid was closed. The instrument was adjusted using 'SET 100' control to obtain '100' displayed on the read out.

\section{Turbidity test sample}

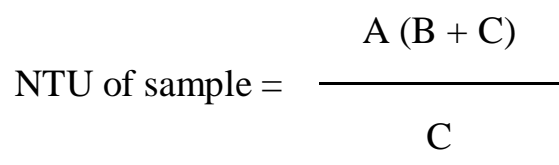




$$
\begin{gathered}
\text { where, } \mathrm{A}=\mathrm{NTU} \text { found in diluted sample; } \\
\mathrm{B}=\text { volume of dilution water in } \mathrm{mL} ; \\
\mathrm{C}=\text { sample volume taken for dilution in } \mathrm{mL}
\end{gathered}
$$

\section{Determining total hardness}

Lake water $(25.0 \mathrm{~mL})$ was pipetted to flask, dilute nitric acid $(5 \mathrm{~mL})$ added followed by buffer solution $(10 \mathrm{~mL}), 1 \%$ sodium sulfide solution $(5 \mathrm{~mL})$ and indicator (3 drops) The mixture was titrated with standard EDTA solution to blue-violet end point.

\section{Determining iron in water}

Colorimetric method using standard solutions of iron (II) sulphate mixed with $0.25 \%$ orthophenanthroline were made to make standard curve. From the calibration curve, absorbance of unknown mixture of iron in water mixed with $0.25 \%$ ortho-phenanthroline were used to read off concentrations.

\section{Determining TSS}

Followed standard method 2540.

It involved filtering water $(50 \mathrm{~mL})$ through weighed filter disk.

\section{Total nitrate in water}

Followed a method in which water $(50 \mathrm{~mL})$ was evaporated to dryness at water bath. The residue was dissolved sodium hydroxide in presence of phenol disulphonic acid and absorbance of solution determined at wavelength of $410 \mathrm{~nm}$.

\section{Determination of dissolved oxygen, $\mathrm{DO}_{5}$}

Followed standard method in which water $(25.0 \mathrm{~mL})$ was placed in reaction flask, and added $2 \mathrm{M}$ sodium hydroxide $(10.0 \mathrm{~mL})$ then $1 \mathrm{M}$ manganese (II) chloride solution $(10 \mathrm{~mL})$ and $10 \%$ potassium iodide. The iodide formed was titrated with standard thiosulfate solution.

\section{Determining pH}

It involved using calibrated $\mathrm{pH}$ meter Jenway $370 \mathrm{pH} / \mathrm{mV} /$ temperature meter.

\section{Determining conductivity}

It involved using calibrated using Jenway 4520 conductivity/TDS meter

\section{RESUlTS AND DISCUSSION}

\section{Physical parameters of lake Bunyonyi waters}

It is common to determine COD, $\mathrm{BOD}, \mathrm{pH}$, turbidity, TSS, nutrient, iron and hardness of water to assess safety of a fresh water resource. Of these parameters, lake Bunyonyi waters sampled on $14^{\text {th }}$ February, 2020 showed COD ranging from 20.8 to $16 \mathrm{mg} \mathrm{L}^{-1}$, turbidity ranging from 25.7 to20NTU, $\mathrm{pH}$ ranging from 8.3 to 7.6 ; iron (II) concentration ranging from 1.1 to $0.8 \mathrm{mgL}^{-1}$; total hardness ranged from 0.22 to $0.19 \mathrm{mg} / \mathrm{L}$; TSS ranged from 3.4 to $2.5 \mathrm{mg} \mathrm{L}^{-1}$; DO ranged from 7.9 to 4.8 
International Journal of Advances in Chemistry (IJAC) Vol. 7, No.1/2/3/4, November 2021

$\mathrm{mg} / \mathrm{L}$; TP ranged from 100.8 to $87 \mathrm{mg} \mathrm{L}^{-1}$ yet $\mathrm{TN}$ ranged from 103.5 to $88 \mathrm{mg} \mathrm{L}^{-1}$ in a distance ranging from $0 \mathrm{~m}$ to $200 \mathrm{~m}$ in the lake. This revealed the impurities were dispersing as we moved in the lake. The environmental protection agency (EPA) published the following water parameters for water safe for human consumption; COD10.0 $\mathrm{mgL}^{-1}$, turbidity $5 \mathrm{NTU}, \mathrm{pH}$ range of 5-9 and iron (II) concentration of $2.0 \mathrm{mgL}^{-1}$. Basing on parameters published, the waters of lakeBunyonyi can be declared polluted.

\section{Variation of total hardness}

The concentration of calcium ions present in lake Bunyonyi water was higher than for magnesium ions for all the samples analyzed indicating that basal rock, agricultural inputs and soils in the catchment areas to the lake contained more calcium than magnesium. Concentrations of calcium and magnesium decreased as distance into the lake increased revealing the lake acted on elements of hardness. The data on total hardness of Bunyonyi water was plotted in Figure 2 below.

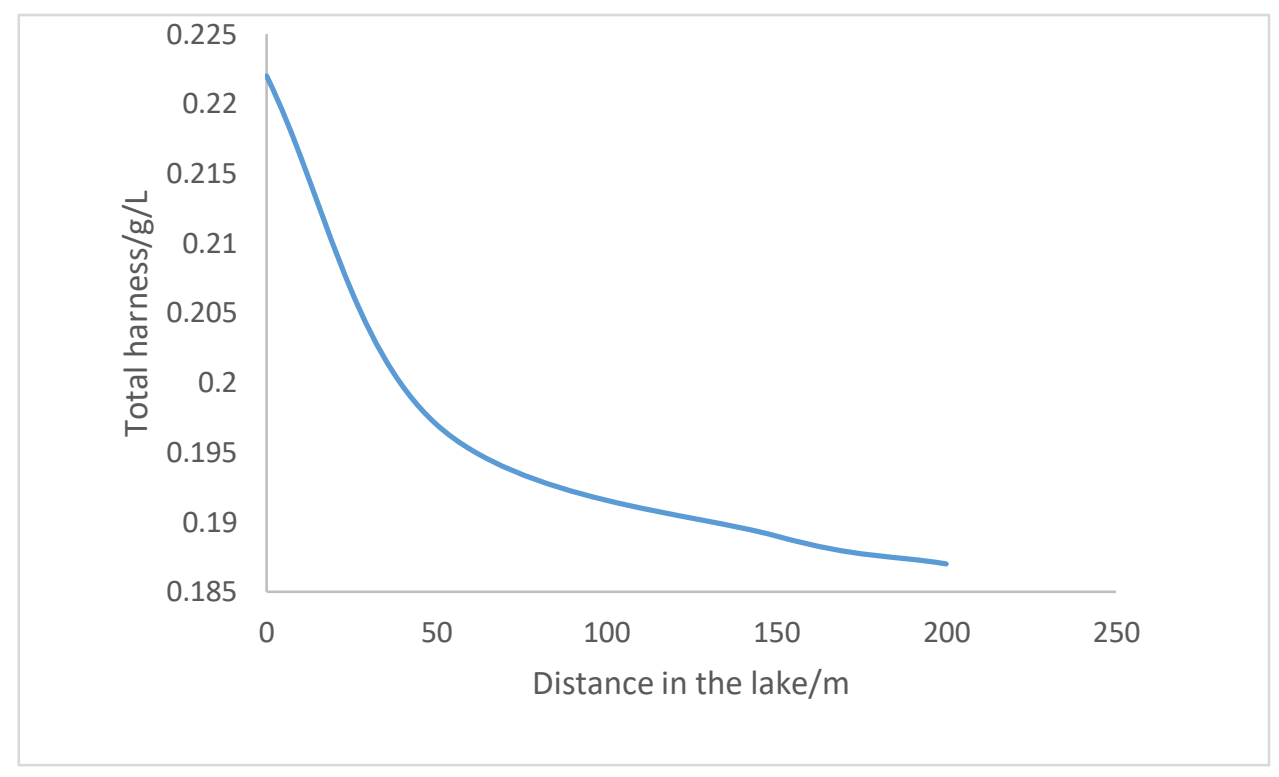

Figure 2. Plot of total hardness against distance in the lake.

From Figure 2 it can observed that concentrations of ions that cause hardness of water decreased as distance increased in the lake. The fall in total hardness may have resulted from transformation of soluble calcium and magnesium salts to insoluble salts that eventually deposited on the lake bed. Similarly, coagulation of metal ions with the colloids suspended in water may have resulted in neutralization of charges with a consequence of removing the ions from water. So, hardness decreased with increase in distance in the lake.

\section{Variations in turbidity of water}

Water turns turbid when there is suspended matter such as particles of clay, silt, finely divided organic and inorganic matter, soluble colored organic compounds, plankton and other microscopic organisms in it. Although we can not rely onturbidity measurements to infer concentration in mass/volume of suspended solids because light scattered by suspended solids depends on size, shape and refractive indices of particles, turbidity expresses the haziness of the water sample tested. Clarity of water is important for human consumption and manufacturing processes such as beverages, and many food products need clear water. So, turbidity of fresh 
water resources like lake Bunyonyi must be monitored regularly because it is the main source of water for domestic use in Kabale town. Water from the lake had high turbidity because it contained impurity sediments. The turbidity of water varied as shown in Figure 3 below.

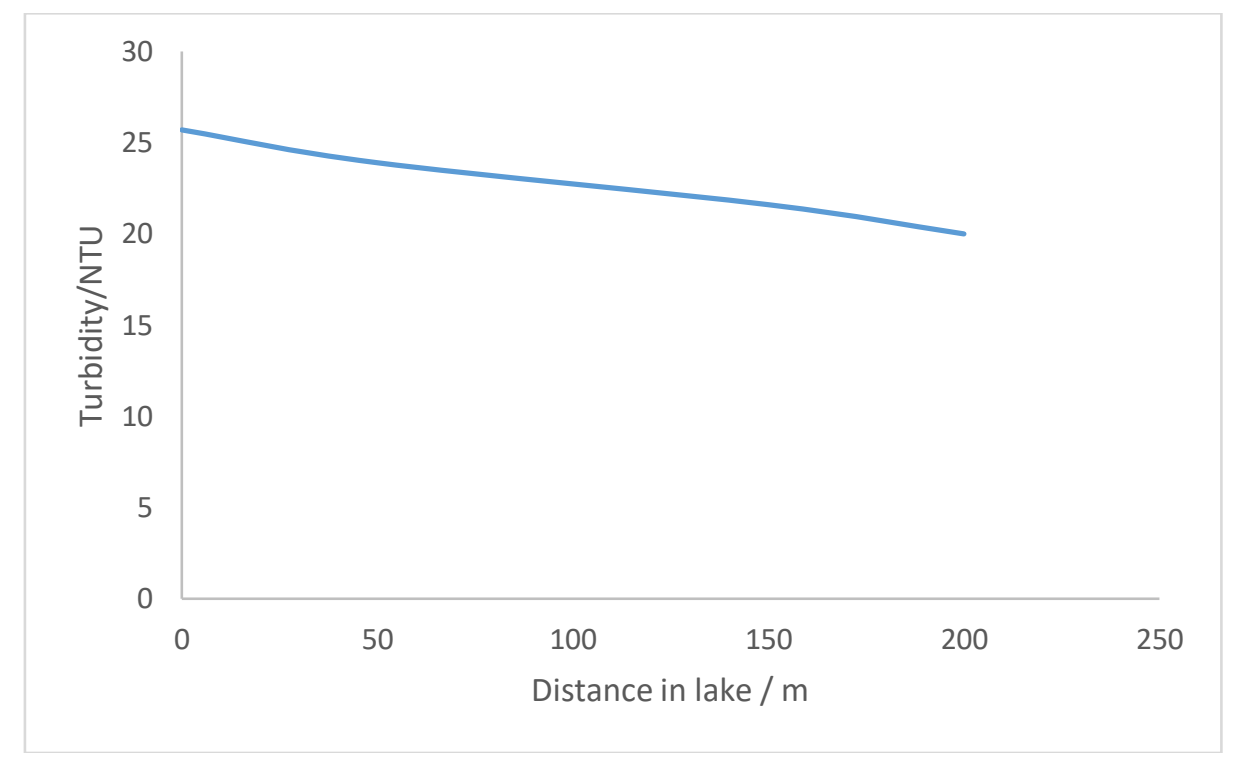

Figure 3. Plot of turbidity of water against distance travelled in lake

Suspended solid sediments enter the lake from the nearby soil surfaces by erosion and haziness of the water body must be higher at places near the soil surface than inside the lake. The turbidity of water decreased as we moved in the lake probably due to dilution as influent got mixed with water in the lake. So suspended solids became dispersed leading to higher clarity. It was reported that dilution or/and neutralization of electrostatic charges on particles in water leads to removal solids from water and this decreases turbidity as shown in graph above(Brachin et al. 2011)

\section{The trend of COD in lake Bunyonyi}

COD expresses the quantity of oxidizable impurities in wastewater or sample of water() and so level of inorganic and organic pollution of lake Bunyonyi was determined from COD. There was decrease in COD with increase in distance into the lake showing level of pollution water decreased. The lake underwent self-purification decreasing oxidizable inorganic and organic pollutants as distance increased in the lake. 


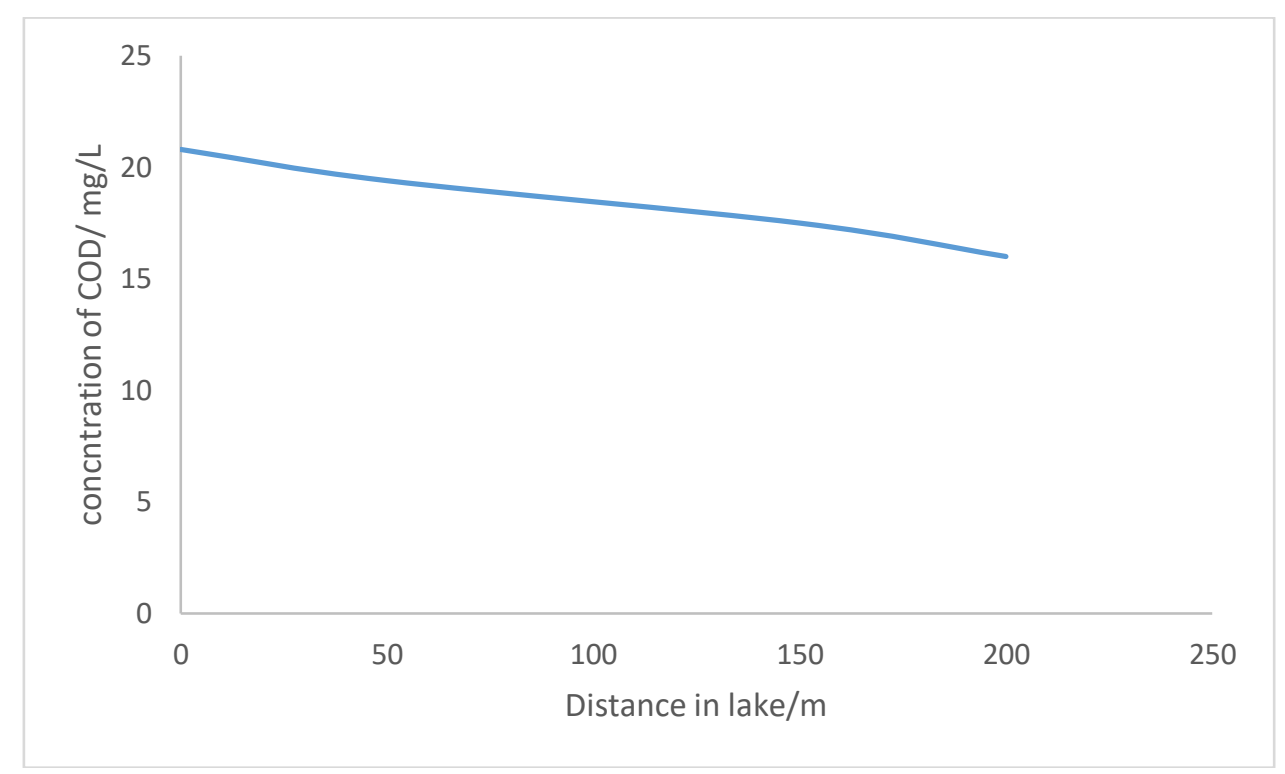

Figure 4. Trend of variation of COD with distance

The decrease in COD as one moves from the shores into the lake resulted from dilution of incoming water by the large volume of water in the lake. Similarly discharge of electrostatic charges on suspended solids in the water must have led to massive precipitation and eventual settling of solids at bottom of the lake and this resulted in further decrease in COD as observed in the trend above (Brachin et al. 2011) This indicated dilution of pollutants in water(Akurut et al. 2017).

\section{Variation of conductivity}

The mean electrical conductivity of lake Bunyonyi decreased from 278 to $245 \mu \mathrm{s} / \mathrm{cm}$ in a distance of 0 to $200 \mathrm{~m}$ in the lake revealing fall in concentration of dissolved salts in water. The electrical conductivity of water body is directly proportional to the concentrations of dissolved salts. So, the high electrical conductivity values observed for Bunyonyiwater were indicative of high concentrations of salts in it (Abdallah et al, 2006;TrivediandGoel, 1986). However, the values obtained were less than maximum level of $1000 \mu \mathrm{S} / \mathrm{cm}$ for fresh water samples. High conductivity values implied presence inorganic ions from salts in water. The conductivity of lake Bunyonyiwater was quite high indicating presence of strong electrolytes. The source of the salts present in the water must be pollution resulting from unsustainable agriculture and contamination of the lake with surface runoff from the rainy events. Running water dissolved fertilizers and salts present in soils to raise the conductivity. The variation of conductivity of water with distance is shown in Figure 5 below 


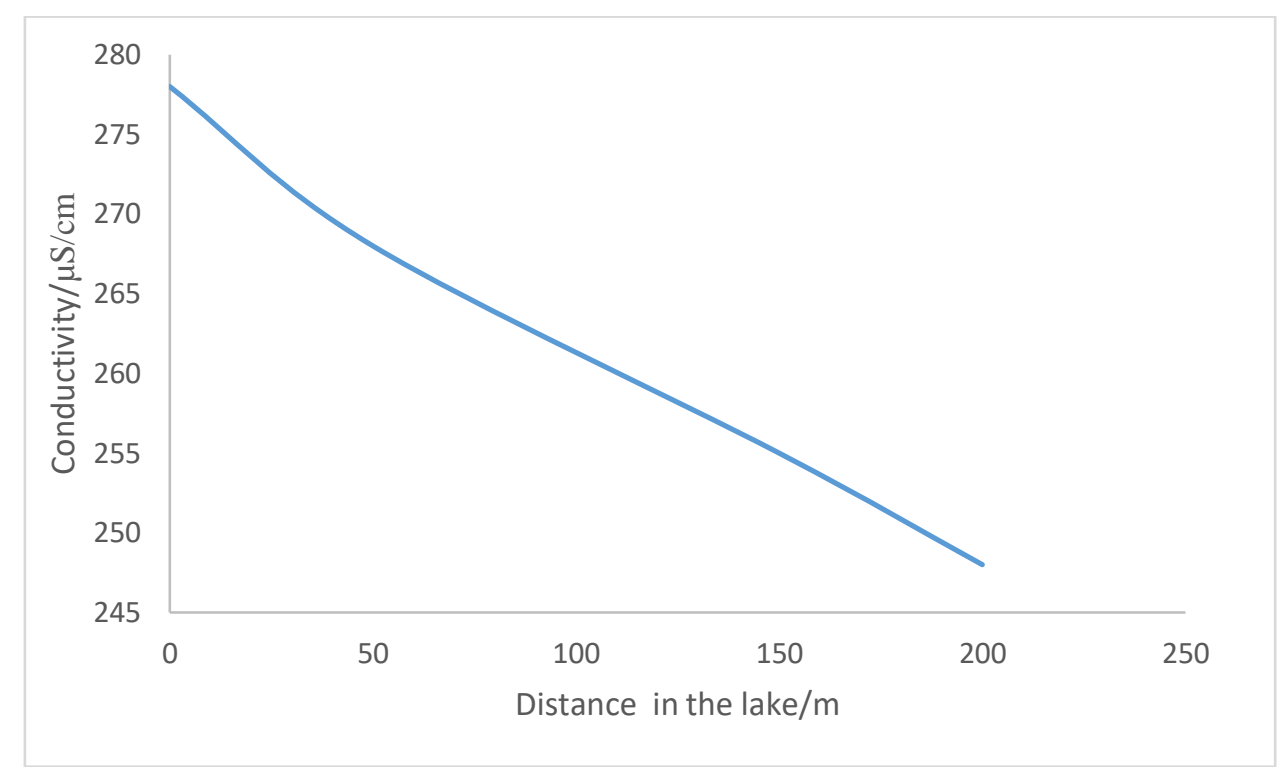

Figure 5. Plot of conductivity versus distance at which water was sampled in the lake

The conductivity of water sampled from lake Bunyonyi decreased as distance into the lake increased revealing the lake was undergoing purification and a similar fall was observed for hardness. Since conductivity arises out of presence of electrolytes and the study had shown presence of calcium and magnesium ions in Bunyonyi waters, it is probable that the fall in concentrations of metal salts with increasing distance in the lake led to fall in conductivity too.

\section{Changes in pH of water with distance in lake}

The $\mathrm{pH}$ of water was high at shores of the lake because water entering had run over soil bearing basic minerals like calcite that readily dissociate to hydrogen carbonate ions in presence of carbon dioxide dissolved in water.

As the lake lies in region with slopes bearing limestone, probable presence of calcium hydrogen carbonate formed as calcite and limestone reacted with carbon dioxide dissolved in running water is under scored. The $\mathrm{pH}$ of water decreased with increase in distance in the lake. This showed that the lake acted on the ions that cause alkalinity of the water in self-purification. During the study the $\mathrm{pH}$ fell from as high as 8.3to as low as8.0.The data on variation of $\mathrm{pH}$ with distance in the lake was plotted in Figure 6 below. 


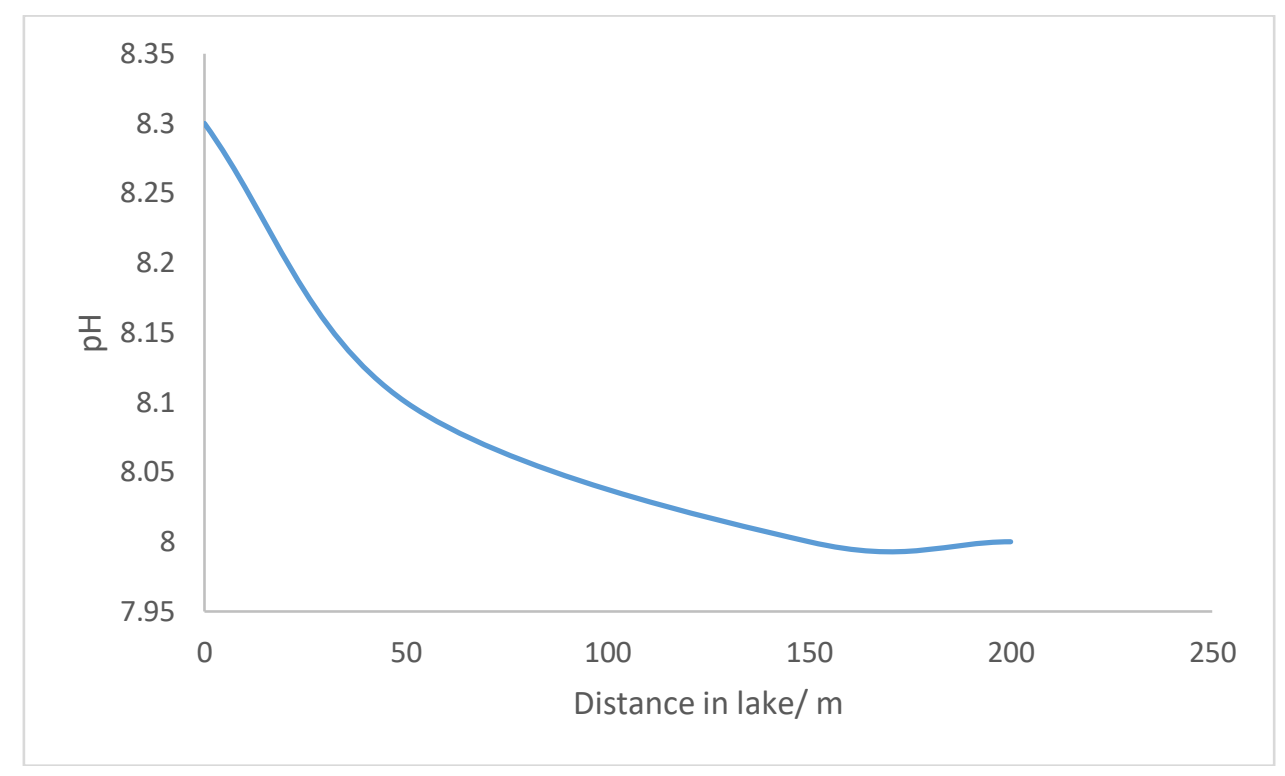

Figure 6. Plot of $\mathrm{pH}$ against distance in the lake

From Figure 6 it can be inferred that the ions that cause alkalinity of the water body decreased as the distance in the lake increased. Since the hydrogen carbonates and carbonates of calcium, magnesium, sodium are known to exist in natural water bodies, in-situ reactions between the ions present the freshwater sample must have resulted in decrease in $\mathrm{pH}$ because sodium salts are less readily hydrolyzed than magnesium or calcium due to lower charge on sodium than calcium or magnesium ions. It was reported that high $\mathrm{pH}$ of water in lakes results from the alkaline salts like carbonate and hydrogen carbonates in soils surrounding the water mass or the bedrock of the lake (Linntech, 2013; MacAdam, \& Parsons, 2004). So high alkalinity of Bunyonyi water results from limestone. Details of alkaline nature of lake Bunyonyi was shown to have no effect on fish productivity (Matagi, 2004; Grant, 2006 and Heydarnejad, 2012).

\section{Changes in concentration of iron in the lake}

Although the EPA set standard for concentration of iron in safe drinking water of $0.3 \mathrm{mg} / \mathrm{L}$ is by far less than what was found in lake Bunyonyi, people living at the lake shores drink the water without treating it. Determining concentration of iron (II) ions in a water sample gives hint on level of heavy metal pollution. It was reported that concentrations of iron exceeding $1.0 \mathrm{mg} / \mathrm{Lis}$ detrimental to freshwater fish (EPA). The concentration of iron decreased from $1.1 \mathrm{mg} / \mathrm{L}$ to 0.8 $\mathrm{mg} / \mathrm{L}$ in a distance of $200 \mathrm{~m}$ from the shore. These low ranges of of concentration of iron can be relied on to assert that lake Bunyonyi water is free from heavy metal pollution because world health organization (WHO) set the range to be between 0.5 and $50 \mathrm{mg} / \mathrm{L}$ The concentration of iron decreased as distance in the lake increased as shown in Figure7below 
International Journal of Advances in Chemistry (IJAC) Vol. 7, No.1/2/3/4, November 2021

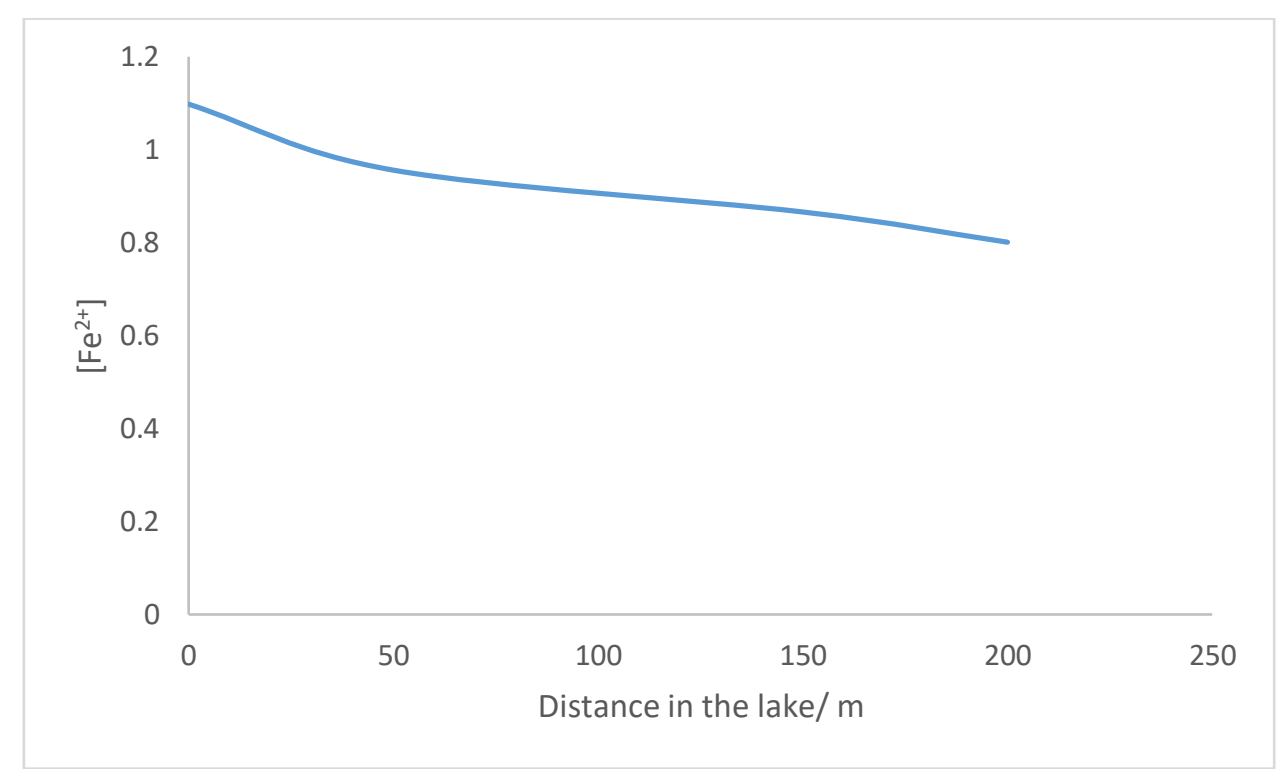

Figure 7. Plot of $\left[\mathrm{Fe}^{2+}\right]$ versus distance in lake

The fall in concentration of iron with increase in distance in the lake was interpreted as a manifestation that the lake through the mechanism of self-purification relieved itself of pollutants. So, the water from lakeBunyonyi is free from iron a major inorganic water quality problem which arises fromFe ${ }^{2+}($ BGS2001).

\section{Change in concentration of dissolved oxygen in the lake}

The concentration of dissolved oxygen decrease with increase in distance from the shores of the lake probably due to lack of strong winds which would easily cause air and water to mix. The lake surface has still air flow as the lake lies between steep hills. The concentration of dissolved oxygen fell from an average value of $7.8 \mathrm{mg} / \mathrm{L}$ to $5.8 \mathrm{mg} / \mathrm{L}$ in a distance of $200 \mathrm{~m}$. The concentration of oxygen in water at surface of a lake nearly $40 \mathrm{~m}$ deep is seen as being very small because the lake is too deep and it is not surprising that the lake bottom is anoxic. This low concentration of oxygen revealed there were micro-organisms in water depleting the oxygen as they decompose matter under the water surface. Fish is only likely to survive in areas of the lake with short depth (Hughes, 1992, Tibihika et al 2016). A plot of concentration of oxygen versus distance is shown in Figure 8 below. 


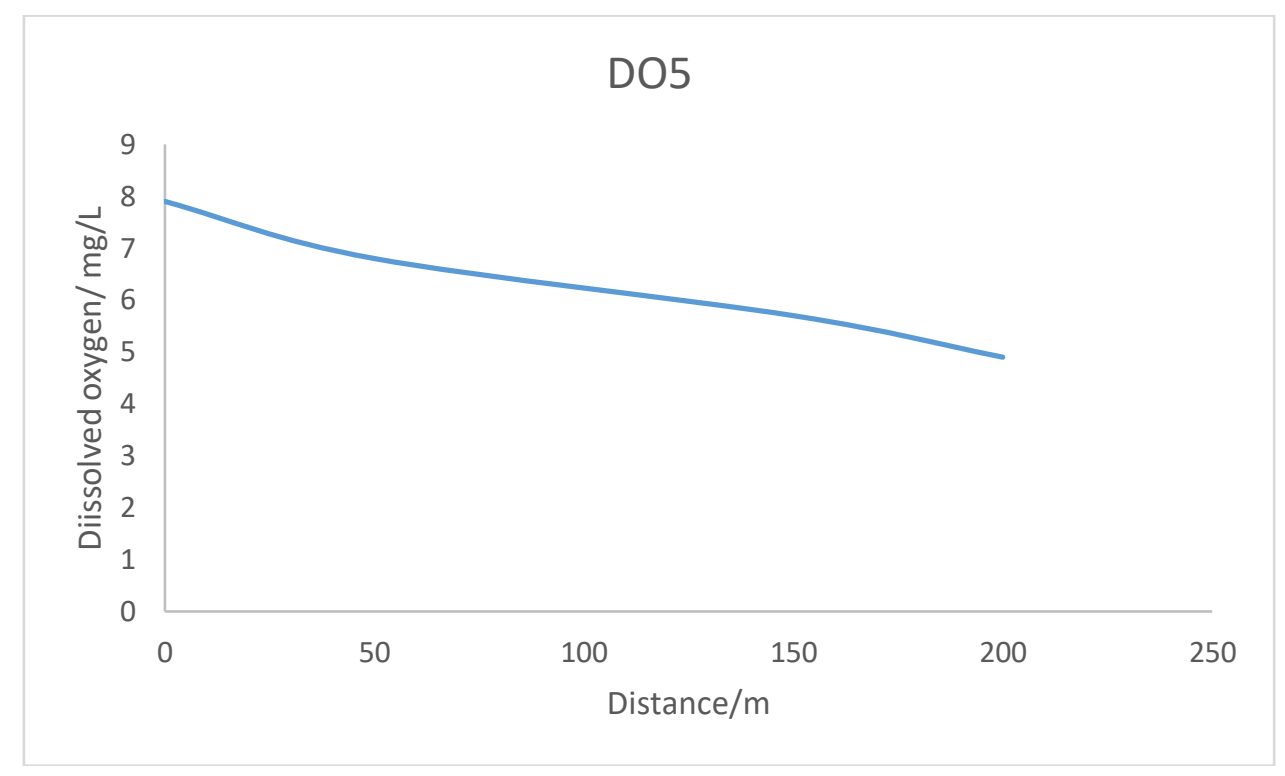

Figure 8. Plot of concentration of DO5 versus distance in lake/m

As shown in Figure 8 above, concentration of oxygen decreased with distance in the lake due to probable increase in quantity of microorganisms in the lake that depleted oxygen revealing the water harbors microbials that deplete oxygen from the water.

\section{Trend of concentration of phosphates in lake}

The total phosphate (TP) concentration of the lake is high probably due to poor agricultural practices of the farmers in the Bunyonyi and Ruhwezamyenda catchment areas following breakdown of the terrace farming in some areas. So erosion of soils from farm land where phosphate fertilizers are used extensively is greatly affecting the lake. The TP values decreased from 100.8 to $87.0 \mathrm{mg} / \mathrm{L}$ in a distance $200 \mathrm{~m}$ from the shores indicating the lake undergoes selfpurification see Figure 9 below.

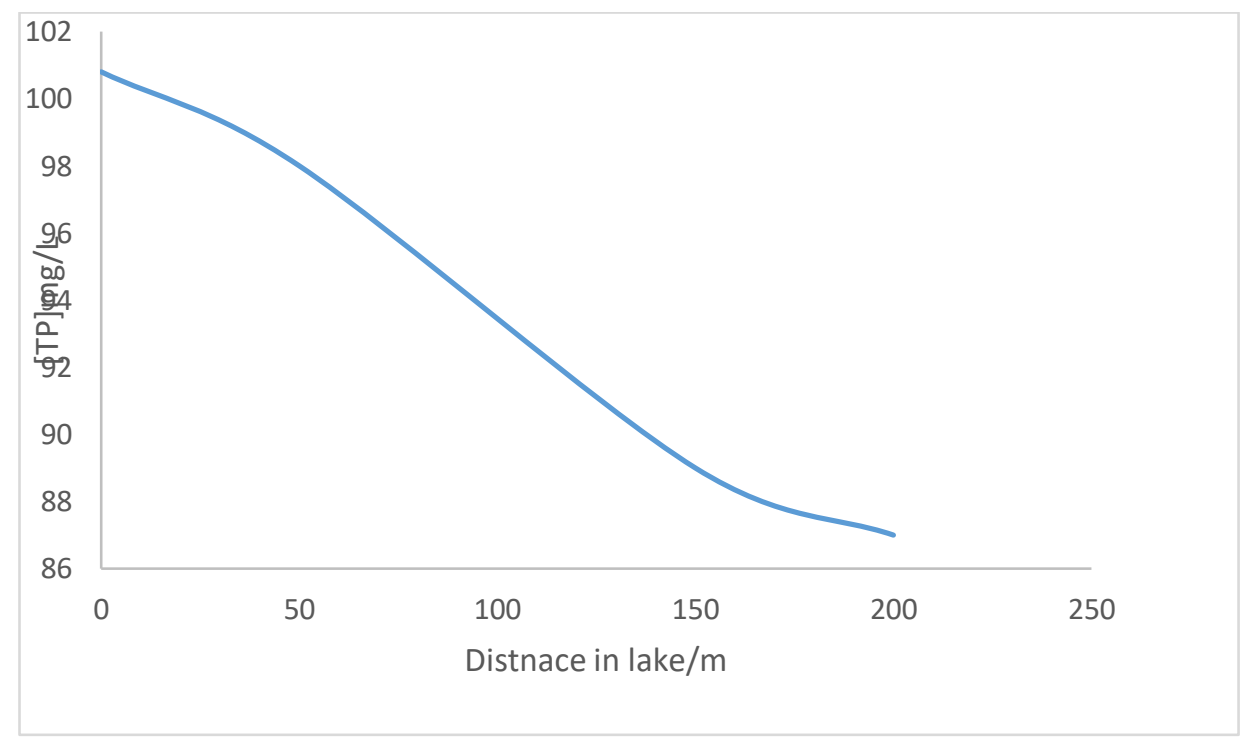

Figure 9. Plot of [TP] versus distance in lake 
The determined phosphate ion concentration in lake Bunyonyi is in agreement with what was published by other workers (Tibihika et al. 2016) and much higher than what was published for lake Victoria and the bays and gulfs on lake Victoria , $0.022 \mathrm{mgL}^{-1}$ for Nyanza gulf (Heckey and Bugennyi, 1992); $0.1-4.5 \mathrm{mgL}^{-1}$ for Murchison bay (Akurut et al. 2017, 2 014). This has revealed that lake Bunyonyi higher suffers phosphate pollution than Lake Victoria. The extent of phosphate pollution for the lake is almost constant over many years as adduced data is in agreement with what was published in 2016 (Tibihika et al. 2016) but requires remedy because nutrients cause algal blooms on water surfaces which deplete oxygen for fish and other aerobic organisms living under the water. Although the very high TP in lake Bunyonyi was reported to to correspond to chlrophyll a in the lake(Tibihika et al, 2016) here should be concern over the use of herbicides near the lake which cause massive death of weeds that enter and settle at bottom of lake, deplet oxygen as they rot and release phosphates to water mass(Mainstone and Parr.2002; Srivassan, 2011). The determined concentration of TP in lake Bunyonyi water is above the maximum recommended to be present in freshwater used for drinking purposes (EPA and this reveals that lake receives phosphate polluted waters containing fertilizers and sewage. The level of phosphate pollution Bunyonyi waters is as high as that for springs in western rift valley of Kenya (Swammy et al. 2018).

As observed from Figure 9 above, the concentrations of the phosphate decreased with increase in distance in the lake due to dilution effects.

\section{Variations in nitrate concentration}

The nitrate/nitrogen concentrations of water sampled in February 2020 ranged from 100.3 to $87 \pm$ $0.3 \mathrm{mgl}^{-1}$ indicating nitrate pollution was very high. The concentrations of total nitrogen determined for Bunyonyi water is consistent with what was observed earlier (Tibihika et al, 2016) but it is much higher than reported values for Lake Victoria in which concentration of nitrogen in the Murchison Bay ranged from as low as 6 to $17 \mathrm{mgL}^{-1}$ (Akurut, et al. 2017) and 12.3 to 18.2 $\mathrm{mgL}^{-1}$ (Mukasa-Tebandeke et al, 2020). The high nitrate pollution of Bunyonyi water is likely to be due to sewage spillage, fertilizer application in farms near or in wetlands that drain water runoff in the Ruhezamyenda catchment. It is also possible that herbicides and algaecides enter waters in lake resulting killing off of weeds and algae in lake water. Mass death green plants in a water mass results in eutrophication as the depletion of oxygen in the lake results in release of much more nitrates than would not occur if the herbicides and/or algaecides never reached the lake (Srinivassan, 2011). The data on changes in concentrations of total nitrate with increase in distance in the lake was plotted in Figure 10 below. 
International Journal of Advances in Chemistry (IJAC) Vol. 7, No.1/2/3/4, November 2021

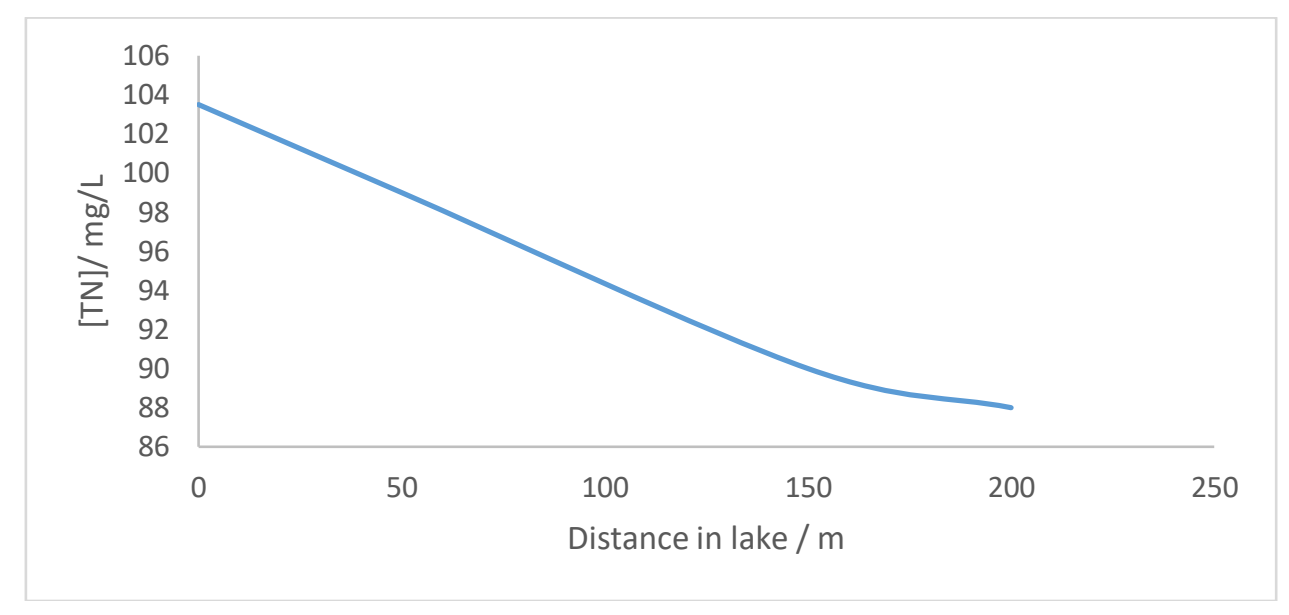

Figure 10. Plot of $[\mathrm{TN}]$ versus distance in lake

From Figure 10 it was observed that total concentration of the nitrate decreased with increase in distance in the lake probably due to dilution or/and neutralization of charges on ions and electrostatic charges on suspended colloids in water resulting in settling of ions in the bed sediments of the lake (Brachin et al. 2011). However, higher concentrations on total nitrate in lakes of Kigezi was explained as corresponding to higher concentrations of chlorophyll in the lake (Tibihika et al. 2016). Higher than $3.0 \mathrm{mg} / \mathrm{L}$ of TN was observed for Bunyonyi water which is the recommended value by WHO. This has been reported to imply that very low concentration of dissolved oxygen in the water and reduces chances of aquatic fauna and flora including fish. High TN indicates that water is polluted by sewage, fertilizers, animal manure and wastewater. High concentrations of TN were reported for water from rivers Awash and Walleme of Ethiopia (Minuta and Jini, 2017; Eliku et al, 2018).

\section{Variations in TSS}

The total concentration of solids suspended in waters of lake Bunyonyi decreased with distance in the lake from 3,3 to $2.7 \pm 0.2 \mathrm{mgL}^{-1}$ indicating lower level of pollution by suspended solids as compared to Lake Victoria (Akurut et al. 2014). As suspended solids concentration critically affects life of fish and other aquatic organisms, low TSS for Bunyonyi water would stimulate fish productivity. The low TSS showed that the flow of surface runoff to both Ruhemyenda and Bunyonyi catchments is slow. So, sediments readily settle down as the water flows to the lake.

The data on TSS and distance in the lake was plotted in Figure 11 below. 


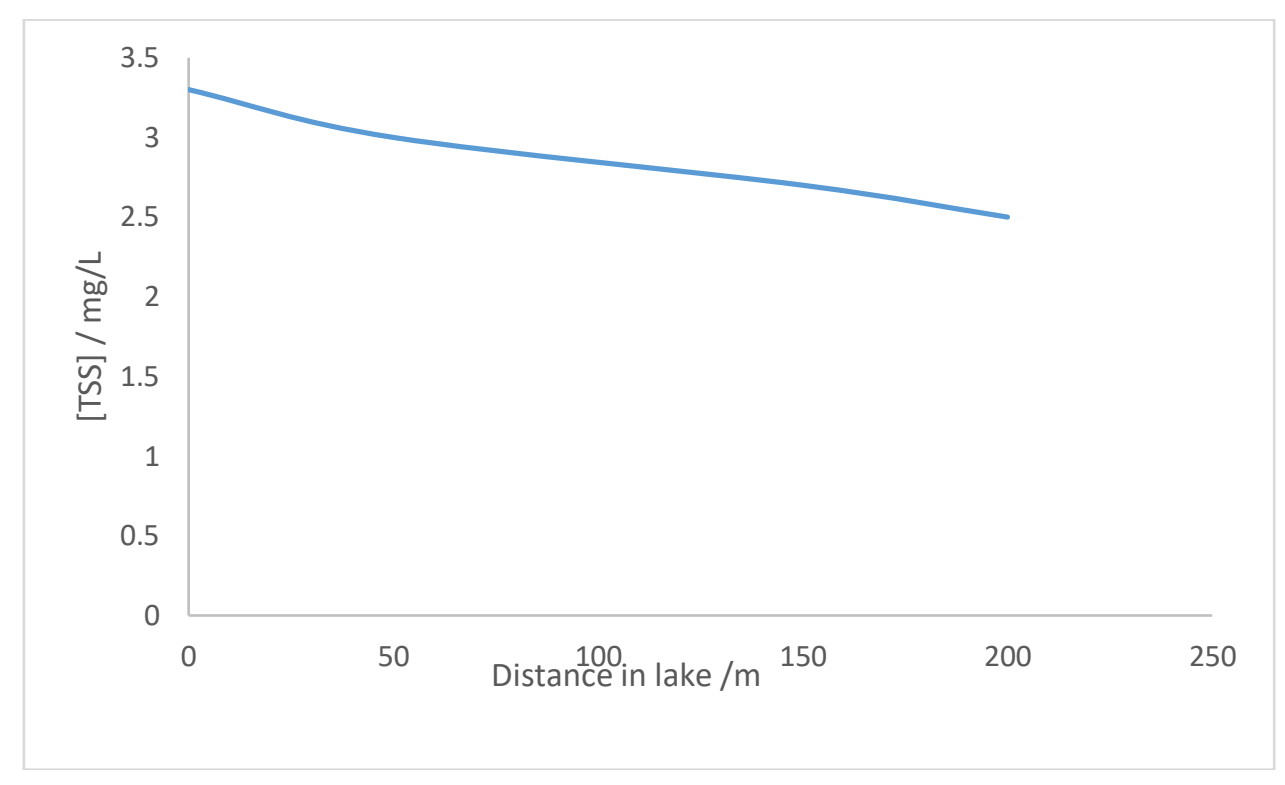

Figure 11. Plot of [TSS] against distance in lake

As observed in Figure 11, the concentration of TSS decreased with increase in distance in the lake. The concentration of total amount solids suspended in Bunyonyi waters decreased with increase in distance in lake from 3.3 to $2.7 \pm 0.2 \mathrm{mgL}^{-1}$ and this was in agreement with what was published earlier (Tibihika et al, 2016) but was ten times less than what was determined for Murchison Bay (Akurut et al. 2018; Mukasa-Tebandeke et al. 2020). The changes in TSS with distance inlake were reported to result from dilution of influent water as it enters the larger mass and neutralization of electrostatic charges on suspended solids as water mixes up (Brachin et al. 2011). Such high TSS as obtain for Bunyonyi water reveals that the water body is polluted by large masses of suspended solids of insoluble and soluble materials.

\section{CONCLUSIONS}

Bunyonyi waters are polluted by nutrients, so electrical conductivity and concentrations of total nitrate and phosphate determined in this study are very high so water is polluted. The COD, electrical conductivity, concentrations of nutrients and TSS decreased as distance increased in the lake due to dilution.

Concentrations changed as follows: COD was $20.8 \pm .0 .03 \mathrm{mg} / \mathrm{L}$ to $16 \pm 0.03 \mathrm{mg} / \mathrm{L}$; total hardness was $16.5 \pm 0.2 \mathrm{mg} / \mathrm{L}$ to $18.6 \pm 0.3 \mathrm{mg} / \mathrm{L}$ total nitrate was $103.5 \pm 2 \mathrm{mg} / \mathrm{L}$ to $88 \pm 3 \mathrm{mg} / \mathrm{L}$; total phosphate was $100.8 \pm .2 .5$ to $87 \pm 3 \mathrm{mg} / \mathrm{L}$; high TSS values from $3.4 \pm 0.1 \mathrm{mg} / \mathrm{L}$ to $2.5 \pm 0.1$ $\mathrm{mg} / \mathrm{L}$ showed contamination of water. As $\mathrm{pH}$ decreased from $8.3 \pm 0.03$ to $7.6 \pm 0.04$ revealed that bases were getting removed. The turbidity dropped from $25.7 \pm 0.3$ NTU to $20 \pm 2$ NTU due settling down of sediments. Iron (II) concentration ranging from $1.1 \pm 0.1$ to $0.8 \pm 0.1 \mathrm{mgL}^{-}$ ${ }^{1}$.Dissolved oxygen decreased from $7.9 \pm 0.3 \mathrm{mg} / \mathrm{L}$ to $4.8 \pm 0.2 \mathrm{mg} / \mathrm{L}$ indicating surface water can uphold life of aquatic organisms. Total hardness ranged from $0.22 \pm 0.05$ to $0.19 \pm 0.05 \mathrm{mg} / \mathrm{L}$ Electrical conductivity was high and ranged from $130 \pm 5$ to $150 \pm 5 \mu \mathrm{S} / \mathrm{cm}$ indicating presence of electrolytes. Waters of Bunyonyi are fresh, less polluted but need to be protected from poor unsustainable agricultural practices to remain safe for human use 
International Journal of Advances in Chemistry (IJAC) Vol. 7, No.1/2/3/4, November 2021

\section{RECOMMENDATIONS}

Schools, urban centers and hotels in the Bunyonyi and Ruhezamynda catchments should not be allowed to drain in the area The terracing of farm land should be strictly observed to reduce influx of nutrients beyond farm land.

\section{ACKNOWLEDGEMENT}

We are greatly indebted to Mr. Ruhara R. Budigi for the instruments used in analyzing the water.

\section{REFERENCES}

[1] Abdullah MH, Ying L, Aris AZ, Park JH. (2007): Water chemistry in downstream region of Tuaran River: A preliminary assessment on seawater intrusion due to sea level rise. In: Park JH, Inam E, Kim KW (eds) Proceedings of the 1st International Workshop on Climate Change Impacts on Surface Water Quality in East Asian Watersheds, Chuncheon, Korea. 2007. p. 100-104.

[2] Abdur R., Zafor M.A and Rahman M. (2013). Surface water quality and risk assessment in the vicinity of Sylhet City, International Journal of Water Resources and Environmental Engineering, Vol. 5(1), 29- 34

[3] Akurut, M., Niwagaba, C. B., \& Willems, P. (2014a). Potential impacts of climate change on precipitation over Lake Victoria, East Africa, in the 21st Century. Water, 6 (Water Resources in a Variable and Changing Climate) (pp. 2634-2659). doi:10.3390/w6092634.

[4] Akurut, M., Willems, P., \& Niwagaba, C. B. (2014b). Assessing the influence of Lake Victoria flux on the Inner Murchison Bay water quality. In C. Brebbia (Ed.), Water Pollution XII, Algarve, Portugal (vol. 182, pp. 51-62). WIT Transactions on Ecology and The Environment, WIT Press. doi:10.2495

[5] Akurut, M.: Niwagaba, C. B. Niwagaba \& Willems, P. (2017) Long-term variations of water quality in the Inner Murchison Bay, Lake Victoria Environ. Monit. Assess 189:22 DOI 10.1007/s10661-0165730-4

[6] Ali, S. M., Khalid, A. R., \& Majid, R. M. (2014). The removal of Zinc, Chromium and Nickel from industrial waste water using Corn cobs ,55(1), 123 - 131

[7] American Public Health Association (1999). American Water Works Association, Water Environment Federation.

[8] American Public Health Association (2003). Standard Methods for the Examination of water and Waste Water, 20th ed. Method $4500 \mathrm{E}$

[9] Ayieko MA, Ngong'a MFO, Tamale A (2010). Climate change and the

[10] Bacchin, P;. A. Marty; P. Duru; M. Meireles ; P. Aimar (2011). Colloidal surface interactions and membrane fouling: Investigations at pore scale Advances in Colloid and Interface Science 164, 2-11

[11]Bracchin, P;. A. Marty; P. Duru; M. Meireles ; P. Aimar (2011). Colloidal surface interactions and membrane fouling: Investigations at pore scale Advances in Colloid and Interface Science 164, 2-11

[12] Bracchini, L., Loiselle, S.A., Tognazzi, A., Dattilo, A.M., Focardi, S.,Cózar, A., (2007). The optical qualities of shallow wetland lined bays in Lake Victoria. Wetl. Ecol. Manag., 15, 509-519.

[13] Banadda, E. N., Kansiime, F., Kigobe, M., Kizza, M., \& Nhapi, I. (2009). Landuse-based nonpoint source pollution: a threat to water quality in Murchison Bay, Uganda. Water Policy, 11, 93-104. doi:10.2166/wp.2009.106.

[14] Batagoda, B.M.S., Turner, R.K., Tinch, R. and Brown, K. (2000). Towards Policy Relevant Ecosystem Services and Natural Capital Values: Rainforest Non-Timber Products. Global Environmental Change Working Paper 2000-06, Centre for Social and Economic Research into the Global Environment, University of East Anglia and University College London.

[15] Beadle LC (1966). Prolonged stratification and deoxygenation in tropical Lakes. I. Crater lake Nkugute, Uganda, compared with Lakes Bunyonyi and Edward. 11(2):152.

[16] Bellir, K., Lehocine, M.B. and Meniai, A.-H., (2013): Zinc removal from aqueous solutions by adsorption onto bentonite. Desalination Water Treatment, 51, 5035-5048.

[17]BGS.(2001) Groundwater Quality: Uganda, London, British Geological Survey. Nottingham, UK, USA

[18] Bilotta, G. S., \& Brazier, R. E. (2008). Understanding the influence of suspended solids on water quality and aquatic biota. Water research, 42(12), 2849-2861. 
[19] Chemining'wam G., Mulagoli, I., Mwonga, S., Ndubi, J., Tum, J. and Tulyamureeba, G. 2005. Kabale apples: Boom or Burst. A study to develop strategies to exploit market opportunities for apple farmers in Kabale, Uganda. www.icra-edu.org/file.php/124/ wd125.pdf. Accessed on 5th April 2020.

[20]Cózar, A., Bergamino, N., Mazzuoli, S., Azza, N., Bracchini, L., Dattilo, A., (2007). Relationships between wetland ecotones and inshore water quality in the Ugandan coast of Lake Victoria. Wetlands Ecology and Management, 15, 499- 507. doi:10.1007/s11273-007-9046-6.

[21] Crerar, S., \& Akurut, M. (2017). Advancing Uganda's NAP Process in the water sector (Scoping field mission report). Internal Unedited Document.

[22] Elias JD, Ijumba JN, Mgaya YD, Mamboya FA (2014). Study on Freshwater Macroinvertebrates of some Tanzanian Rivers as a Basis for Developing Biomonitoring Index for Assessing Pollution in Tropical African Regions. J. ecosyst. 8(2014):985389.

[23] Eliku T,and Leta S. (2018)Spatial and seasonal variation in physicochemical parameters and heavy metals in Awash River, Ethiopia. Appl Water Sci 2018, 8: 177

[24] Grant WD (2006). Alkaline environments and biodiversity, in extremophiles. Encyclopaedia of life support systems (EOLSS). G. Charles and G. Nicolas. Oxford, UK, Eolss Publishers.

[25] Green J (2009). Nilotic Lakes of the Western Rift. 17 King Edwards Grove, Teddington, Middx. TW11 9LY, UK.

[26] Green J (1976). Changes in zooplankton of Lakes Mutanda, Bunyonyi and Mulehe (Uganda). Freshwater Biol. 6:433-436.

[27] Gupta T, Mrinal P (2013). The seasonal variations in ionic composition of pond water of Lumding, Assam, India. Curr. World Environ. 8(1):127-131.

[28]Haande, S., Rohrlack, T., Semyalo, R. P., Brettum, P., Edvardsen, B., Lyche-Solheim, A. (2011). Phytoplankton dynamics and cyanobacterial dominance in Murchison Bay of Lake Victoria (Uganda) in relation to environmental conditions. Limnologica - Ecology and Management of Inland Waters, 41, 20-29. doi:10.1016/j.limno.2010.04.001. 22 Page 16 of 17 Environ Monit Assess (2017) 189:22

[29]Hecky RE, Mugidde R, Ramlal PS, Talbot MR, Kling GW (2010).Multiple stressors cause rapid ecosystem change in Lake Victoria. Freshwater Biol. 55(Suppl. 1):19-42.

[30] Hecky, R.E. and Bugenyi, F.W.B. (1992): Hydrology and chemistry of the African great lakes and water-quality issues: problems and solutions. Mitt Int Ver Theor Angew Limnol 23:45-54

[31] Heydarnejad MS (2012). Survival and growth of common carp (Cyprinus carpio L.) exposed to different pH levels. Turk. J. Vet. Anim. Sci. 36(3):245-249.

[32] Hughes RH, Hughes JS (1992). A directory of African Wetlands. IUCN, Gland, Switzerland and Cambridge, UK/UNEP, Nairobi, Kenya/WCMC, xxxiv 820 p, 48 maps.

[33] IEPA (Illinois Environmental Protection Agency) (1998). Lake Notes. Common lake water quality parameters. DWPC-Lake and Watershed Unit, P.O.Box 19276, Springfield, Illinois 627949276:217/782-3362.

[34]Jiang, J.Q., Zeng, Z., and Pearce, P., (2004): Evaluation of modified clay coagulant for sewage treatment. Chemosphere, 56, pp 181-185.

[35] John Wiley and Sons Inc., ( 1993) Aquatic Pollution. E.A. Laws., ,. 2nd ed. pp 148-149. New York

[36] Kamanyi JR, Ndawula LW, Magumba M (2006). Preliminary survey of Lakes Mutanda and Mulehe Fisheries. Fisheries Resources Research Institute (FIRRI) P. O. Box 343, Jinja-Uganda.

[37] Katunzi EF (2001). Satellite Lakes, rivers and dams as refugia for the endangered fish species of Lake Victoria. Paper presented at the National Scientific Conference held in Mwanza, Tanzania, August 2001.

[38] Kennedy, K.K., Maseka, K.J. and Mbulo, M. (2018): Selected adsorbents for removal of contaminants from wastewater: Towards engineering clay minearls. Open journal of applied sciences 8, 355-369 http://doi.org/10.4236/ojapps.2018.8807

[39] Kizito YS, Nauwerck A, Chapman LJ, Koste W (1993). A Limnological survey of some Western Uganda Crater Lakes. Limnologica 23(4):335-347.

[40] Kristan, M., Abeku, T.A., Beard, J., Okia, M., Rapuoda, B., Sang, J. and Cox, J. 2008. Variations in entomological indices in relation to weather patterns and malaria incidence in East African highlands: implications for epidemic prevention and control. Malaria Journal 7 (231): 14752875.

[41]Likens GE (2010). Lake Ecosystem Ecology, Academic Press, San Diego, Calif, USA.

[42] MacAdam, J., \& Parsons, S. A. (2004). Calcium carbonate scale formation and control. Re/Views in Environmental Science \& Bio/Technology, 3(2), 159-169. 
[43] Machiwa, P. K. (2003). Water quality management and sustainability: the experience of Lake Victoria Environmental Management Project (LVEMP) — Tanzania. Physics and Chemistry of the Earth, Parts $\mathrm{A} / \mathrm{B} / \mathrm{C}, 28(20), 1111-1115$.

[44] Magumba MK (2000). Physical-chemical algal composition and primary production in the four Kisoro minor Lakes. In proceedings of the workshop on: The fisheries of Kisoro Minor Lakes.

[45] Mainstone C P and Parr. W(2002). Phosphorus in rivers - ecology and management. Sci. Tot. Environ., (282/283): 25-47.

[46] Matagi SV (2004). "A biodiversity assessment of the Flamingo Lakes of eastern Africa." Biodiveristy 5(1):13-26.

[47] Mavuti KM, Litterick MR (1991). Composition, distribution and ecological role of zooplankton community in Lake Victoria, Kenya waters. Verh. Intern. Verin. Limnol. 25:846-849.

[48] Minuta T,and Jini D. (2017): Impact of effluents from wet coffee processing plants on the Walleme River of Southern Ethiopia. Res J Environ Toxicol 2017, 11 : 90-96.

[49] Mukasa Tebandeke IZ, Karume I, Wasajja HZ, Nankinga R. (2020) : Improving Quality of Water from Murchison Bay using Clay from Chelel, Kapchorwa District, Uganda. Journal of Advances in Chemistry 17, 1-30 ISSN: 2321-807X https://www.rajpub.com/index.php/jac

[50] Osiru, D.S.O. (2006). Report on crop/farming systems and PRA. Prepared for FAO Transboundary Agro-Ecosystem Management Programme (TAMP). Makerere University. Retrieved from http:// www.fao.org/fileadmin/templates/nr/images/resources/pdf_documents/kagera/uganda/ug _ crop_farming_systems.doc

[51]Rashid R, Pandit AK (2014). Macro-invertebrates (Oligochaetes) as indicators of pollution: A review. J. Ecol. Nat. Environ. 6(4):140-144.

[52] Rügner, H., Schwientek, M., Beckingham, B., Kuch, B., \& Grathwohl, P. (2013). Turbidity as a proxy for total suspended solids (TSS) and particle facilitated pollutant transport in catchments. Environmental earth sciences, 69(2), 373-380.

[53] Rutner-Kolisko A (1974). Planktonic rotifers: Biology and taxonomy, Biological Station Lunz of the Austrian Academy of Science. E. Schweizerbart'scheVerlagsbuchhandlung.

[54] Semyalo R, Nattabi JK (2009). Diel vertical migration of zooplankton in a eutrophic bay of Lake Victoria. Hydrobilogia 635:383-394.

[55] Singh, N., Nagpal, G., Agrawal, S. and Rachina (2018). Water purification by using various adsorbents: A review. Environmental technology and innovation 11, 187-240. http://doi.org/10.1616/j.eti.2018.05.006.

[56] Srinivasan, R.. (2011): Advances in application of natural clay and its composites in removal of biological, organic, and inorganic contaminants from drinking water. Advances in Materials Science and Engineering, 11, 1-17.

[57] Ssebiyonga, N., Erga, S. R., Hamre, B., Stamnes, J. J., \& Frette, Ø. (2013). Light conditions and photosynthetic efficiency of phytoplankton in Murchison Bay, Lake Victoria, Uganda. LimnologicaEcology and Management of Inland Waters, 43(3), 185-193.

[58] Swamy A.; Terer Erick Kipngetich, Magut Hillary and T. (2013) CODEN (USA): IJPLCP ISSN: 0976-7126 Int. J. of Pharm. \& Life Sci. (IJPLS), 4(7), 2828-2833 2829

[59] Tamatamah, R. A., Hecky, R. E., \& Duthie, H. (2005). The atmospheric deposition of phosphorus in Lake Victoria (East Africa). Biogeochemistry, 73, 325-344. doi:10.1007 /s10533-004-0196-9. USDA (2015). USDA. http://www.pecad.fas.usda. gov/lakes/images/lake0314.TPJO.2.txt. Accessed 12 May 2015.

[60] Tibihika PDM, Barekye A, Byakora E (2015). Fish species composition, abundance and diversity of Minor Lakes in South Western Uganda/Kigezi Region. Int. J. Sci. Technol. 4(5).

[61] Tibihika, P.D.M.; Okello, W.; Barekye, A.; Mbabazi, D.; Omony, J. and Kiggundu, V.: (2016) Status of Kigezi minor Lakes: A limnological survey in the Lakes of Kisoro, Kabale and Rukungiri Districts International Journal of Water Resources and Environmental EngineeringVol. 8(5), pp. 60-73, June 2016 DOI: 10.5897/IJWREE2016.0645 Article Number: 5F4CDCD59074 ISSN 2141-6613

[62] Trivedi R.K, and Goel P.K. Chemical and biological methods for water pollution studies. Environmental Publications, Y. K. College of Science, Karad, India. 1986. p. 250.

[63] Turner, R.K., van den Bergh, J.C.J.M., Söderqvist, T., Barendregt, A., van der Straaten, J., Maltby, E. and van Lerland, E.C. (2000). The values of wetlands: Landscape and institutional perspectives. Ecological Economics, 35: 7-23.

[64] U.S. Environmental Protection Agency, Eutrophication: http://www.epa.gov/maia/html/eutroph.html 
International Journal of Advances in Chemistry (IJAC) Vol. 7, No.1/2/3/4, November 2021

[65]U.S. Environmental Protection Agency, National Nutrient Guidance: http://www.epa.gov/ost/criteria/nutrient/guidance/

[66] Verma, A., Wei, X., \& Kusiak, A. (2013). Predicting the total suspended solids in wastewater: a datamining approach. Engineering Applications of Artificial Intelligence, 26(4), 1366-1372.

[67] Water Research Center. Water Testing Total Dissolved Solids Drinking Water Quality. 2019. https://waterresearch.net/index.php/water-treatment/tools/total-dissolved-solids. Accessed 11 June 2020

[68] Waya RK, Chande AI (2004). Species composition and biomass estimates of zooplankton in some water bodies within Lake Victoria basin. Tanz. J. Sci. 30(1).

[69] Wetzel GR (1975). Limnology. W. B. Saunders, Filadelfia, Pensilvania.743p

[70] WHO (2008). Guidelines for drinking-water quality, 3rd edition First Addendum to the 3rd edition Volume 1 recommendations (Vol. 1) WHO. Geneva, Recommendations.

[71] World Health Organization, WHO (2004). Guidelines for Drinking Water Quality, vol. 1, 3 rd ed. World Health Organization, Geneva, Switzerland.

[72] World Health Organization, WHO (2008). Guidelines for Drinking Water Quality, Incorporating the first and second Addenda. vol. 1, 3rd ed. World Health Organization, Geneva, Switzerland. 20. Oeteman, B.C.J (1980).

[73] Worthington EB, Ricardo CK (1936). The vertical distribution

[74] Worthington EB (1932). A report on the fisheries of Uganda investigated 